\title{
AMBIENTE, ESPAÇO, PAISAGEM
}

\author{
MIRANDA MARTINELLI MAGNOLI*
}

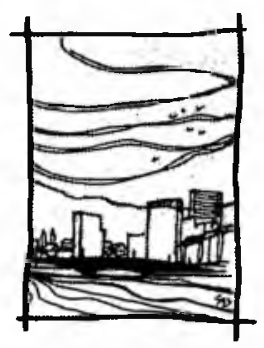

Universalidade e diversificação da questão ambiental; qualidade do ambiente ou injunções econômicas e interesses políticos? Modelo de desenvolvimento brasileiro tem a qualidade de vida de sua população como meta?

Meio ambiente humano e ecologia: a amplitude, qualidade e extensão das transformações produzidas pelas sociedades humanas; o subsídio da ecologia: os ecossistemas enquanto propiciadores de recùrsos: utilização de recursos e de espaço como modelos imbricados.

Algumas questões para debate e avanço na questão ambiental.

A questão ambiental é uma questão universal; comentada, levantada, descrita, documentada e "recomendada" por todos os países do universo nos últimos vinte e cinco anos.

No entanto ela é. no mínimo, diversificada nesses países todos. E. essa diversificação se apresenta em dois blocos iniciais: o dos países ricos e o dos países pobres, assim vistos enquanto desenvolvimento econômico. É por essa ótica, a ótica do desenvolvimento econômico, que vem à tona a questão ambiental. E, por essa ótica, as posições entre os dois blocos de nações são totalmente conflitantes.

Os recursos naturais da terra e a apropriação pelos povos ocupou a década de 70 com concepções freqüentemente desprovidas de sentido de realidade e carregadas de intensa desigualdade. A posição dos países ricos, veiculada de todas as maneiras, em diversos aspectos, em vários níveis não conseguiu porém obscurecer o fato que, nos países em desenvolvimento, é justamente o esforço para esse desenvolvimento. para sair da "poluição da pobreza" o principal causador dos impactos e degradações da natureza. Deu margem a entendimentos os mais estranhos. desde "a poluição e degradação como custo do progresso" ou à redução da questão ambiental à "poluição" resultante do impacto da industrialização, e, por consequiência. privilégio das naçōes ricas. 
Injunções econômicas e interesses políticos foram muito superiores que as preocupações com a qualidade do ambiente nas veiculações dos vários delegados dos países desenvolvidos nos anos 60 e 70 .

Não foram poucos os esforços que os demais países tiveram que se propor para clarificar as principais questões; e estas vão desde identificar que a poluição é muito mais resultante da ação das nações ricas, enquanto não respeitam os recursos naturais das nações em esforço de desenvolvimento; até conseguir passar à compreensão de que não pode haver desenvolvimento econômico realmente se não se incorporar a dimensão ambiental, o que faz com que a questão ambiental seja muito mais importante para os países pobres e, justamente para as maiorias pobres de suas populações do que para os demais países.

O processo brasileiro de desenvolvimento, pelo modelo adotado, em facetas e nuances pouco diferentes. sempre foi importante incrementador do impacto sobre o ambiente. Basta uma leitura dos planos de desenvolvimento exarados nas décadas anteriores sob nomes diversos para se perceber como viriam a ser intensas e extensas as pressões sobre o espaço do território, sobre as estruturas sociais e produtivas da nação. Essas pressōes se fariam sentir, e assim foi e está sendo, sobre todos os setores, quer agrícola, industrial e o insumo energético básico, o setor energético. E se faria sentir em todos os ambientes, rural ou urbano, quaisquer fossem as regiões, os recursos, as localizações, em vista de intrincada trama de inter-relações de mecanismos complicados e sutis que o modelo de desenvolvimento imposto carregou consigo.

Em nível mundial a diversificação em dois blocos de posições conflitantes foi o suficiente para identificar aspectos fundamentais da questão.

Assim posto pode parecer simples enfrentar o desafio. Só é simples em declarações:

"Realizar o desenvolvimento sem deterioração da qualidade de vida. e. em particular sem devastação do patrimônio de recursos naturais do País" é item do II PND, divulgado em 1974.

Em nível de país, as diversificações se apresentam de maior amplitude. Independentemente até das diferenças do quadro natural advindas da proporção, da "continentalidade" do país são as diferentes formas com que se apresentam os quadros sócioeconômicos que exigem cuidados de avaliação. Não se poderá unificar o rol de problemas ambientais. Basta lembrar, mesmo de forma genérica. as características populacionais e a ocupação do território para avaliar que os problemas ambientais se apresentam diversamente no espaço do território. 
Fundamentos naturais e diretrizes econômicas adquirem certo grau de solidariedade que pode identificar questōes ambientais num grande esboço macrorregional. É do geógrafo Prof. Carlos Augusto Figueiredo Monteiro a caracterização de sete grandes unidades de problemas ambientais:

1 - O Sudeste brasileiro. centro econômico e de maior peso na estrutura social do país. com os maiores indícios de ocupação efetiva do solo e a área mais dinâmica do ponto de vista industrial e urbano.

Os problemas ambientais são de grande magnitude, em geral de superutilização dos recursos; sob esse aspecto e, de maneira superficial e grosseira, poder-se-ia dizer que se pode fazer alguma comparação com os centros dos países desenvolvidos. Porém a observação das estruturas econômico-sociais resultantes mostra quão grosseira é a comparação: as desigualdades são gritantes e proporcionais ao peso econômico que a região adquire.

2 O Brasil meridional, onde as áreas metropolitanas e os aspectos de industrialização não apresentam a gravidade de São Paulo e Rio de Janeiro. Nas áreas rurais, apesar de uma das organizações mais elevadas dentro dos padrões nacionais, não deixam de apresentar a deterioração de várias bacias hidrográficas, a devastação florestal, especialmente das matas de Araucária, o assoreamento das baixadas paranaenses e o desgaste violento das áreas de mineração de carvão no Rio Grande do Sul e Santa Catarina.

3 - O espaço mineiro. do Espírito Santo e sul da Bahia. em que talvez o maior impacto esteja nos antigos núcleos litorâneos e as modificações da estrutura sócioeconômica decorrentes do desmatamento da reserva de floresta atlântica e a introdução do turismo especulativo junto com o "pólo madeireiro" introduzido sem apoio técnico.

4 - O Nordeste, parte dos domínios tropicais e é caracterizado nesses domínios pelos períodos alternadamente secos e chuvosos. Perifericamente úmido, junto ao litoral e interiormente semi-árido tem um regime pluvial irregularmente oscilante: às secas dramáticas se alternam catastróficas enchentes. Porém. por mais graves que possam parecer esses aspectos do suporte, aqueles decorrentes da ordem sócioeconômica são bem mais graves. Possibilitam até que o Prof. Carlos Augusto Figueiredo Monteiro declare que "a natureza continua fornecendo um conveniente álibi para a inoperância do subsistema social e a estrutura econômica carente e subdesenvolvida"

5 O meio Norte, interface entre o Nordeste e a Amazônia, tem, até há poucos anos, mais expulsado populações do que conseguido retê-las em seu espaço regional. 
6 A Amazônia, caso a parte em relação a todos os demais aspectos e caracterizações, exigindo seja tratada mesmo que de forma genérica e preliminar como uma situação única, face às especificidades quer do fundamento natural quer dos processos históricos que envolveram sempre elementos de intensa e grande pressão. A visão que tem presidido a política de desenvolvimento da Amazônia não é absolutamente de consenso. Por maiores que sejam as questōes ecológicas é a sociedade civil que se movimenta pela participação nas definições das questōes básicas da política de desenvolvimento da Amazônia.

7 - O Centro-Oeste, alvo da expansão do povoamento e da ocupação total do espaço nos últimos vinte anos, reunindo cerrados com áreas florestais importantes e o pantanal, passou a integrar a mais ampla área de expansão da fronteira agrícola em tão curto prazo.

Fica Rondônia e a faixa norte de Mato Grosso como outra interface da Amazônia com o Centro-Oeste. Estes espaços. nos últimos dez anos, foram objeto da mais concentrada ação de ocupação de que se tem conhecimento desde que se deflagrou a questão ambiental em nível internacional e nacional. São ações multinacionais e nacionais, ligadas a empresários e contando com fluxos de migrantes oriundos de excedentes populacionais decorrentes da falta de solução dos problemas nos seus locais de origem.

Entendo o meio ambiente humano como o resultado das interações das sociedades humanas com o suporte, a base física e biológica que as envolve. contribuindo este suporte, esta base. de diferentes maneiras para sua subsistência biológica e espiritual. Este suporte, base física e biológica, já tem uma história de interações; desde o aparecimento do homem é objeto da ação do homem, alterando essa base. Daí, poderá se sintetizar a concepção de ambiente como a interação da sociedade com o supone físico, quẹ tenha aparência comumente denominada "natural" ou construída. A interação se dá no espaço geográfico pelas adaptações, transformações, readaptações e novas transformações das sucessivas formas encontradas, elaboradas e reelaboradas. A essas conFORMAções, conFIGURAções, carregadas da interação social com o suporte temos denominado PAISAGENS.

É decorrência da concepção de meio ambiente observar que intervém no processo de criação das interaçōes, componentes sociais. culturais. econômicos. físicos e biológicos: aspectos desses componentes passam a conformar e condicionar esse meio. aperfeiçoando-o ou deteriorando-o em relação ao bem-estar humano.

A finalidade básica do estudo do meio ambiente humano deve ser o aperfeiçoamento da qualidade de vida humana. 
Não se pode chegar a esse objetivo por percursos que implicam uma deterioração generalizada do meio físico ou biológico, que contribui para sua existência. seu sustento. Também não se pode chegar por percursos que impliquem na falta de aproveitamento de potencialidades naturais existentes deixando de contribuir para o bem-estar geral.

A ecologia, até abrangências conceituais bastante recentes. vinha. como ciência, selecionando e combinando conhecimentos procedentes de diferentes especialidades para extrair conclusões globais sobre a estrutura, funcionamento, dinâmica e evolução no espaço e no tempo, das comunidades vivas e o "entorno" físico em condições "naturais" ou modificadas, em diversos graus. pelo homem.

Ecossistema é um conceito fundamental nessa relação comunidades e "entorno" Ecossistema não é entidade física ou uma extensão geográfica. É um nível de organização que envolve populações e comunidades com seus meios físicos e fluxos energéticos. Pode-se atribuir aos ecossistemas alguns vagos limites físicos ou geográficos, segundo os objetivos do estudo que se pretenda. Porém, o que será objeto de investigação são as inter-relações que aparecem, as estruturas que se formam e as funções dos elementos.

Sob esse específico enfoque da ecologia, o homem se diferencia dos demais elementos do ecossistema face à amplitude, qualidade e extensão geográfica com que produz mudanças.

É costumeiro que o ano de 1760. dado como início da Revolução Industrial. seja indicado como marco das modificações da paisagem, nas diversas e sucessivas utilizações do solo e nos diversos estímulos e estilos do desenho de paisagismo. A persistência do marco, posto quase como origem das transformações, leva a que freqüentemente se julgue que é nesse período que o homem passou a exercer um papel nas alterações da face da terra, passou a exercer transformações, fazer uso dos recursos naturais, escavar o subsolo à procura de minerais, despejar resíduos. detritos. escombros. Desse marco é que teria passado a esgotar alguma fonte de recursos, sendo obrigado a se transferir para outro lugar para uso do mesmo recurso ou a criar novos meios de responder às necessidades com outros recursos. A poluição das águas é vista como uma deterioração contemporânea; as mudanças de áreas com perdas de espécies vegetais e minerais, a poluição do ar. a criação de outros espaços a custa de brejos e pântanos. ou a criação de diques e lagos como reservatórios de armazenamento de água seriam dos últimos dois séculos. Mais comum ainda é se pensar que as limitações por lei, formas diversas de controle do homem, sobre a utilização dos recursos só há poucas décadas começaram a ser elaboradas. 
E assim também são vistos os efeitos sobre a paisagem; modificações profundas, modificações do caráter da paisagem são avaliadas como recentes.

Na realidade, desde a Idade da Pedra. a produção de artefatos, as transformações na lavoura. na pecuária, são atividades próprias do homem: durante largos períodos contínuos grupos humanos aplicaram energia para suas atividades. A criação de fontes mais eficazes de energia teve sempre papel essencial nas transformações. A energia diretamente humana, ou auxiliada por ferramentas criadas para incrementar os efeitos, ou a energia a vapor, do petróleo, elétrica, nuclear são parte do processo de transformações.

A diversificação, complexidade. e maior alcance dos vários componentes postos em ação é que faz com que os impactos dos processos de intervenção humana adquiram a abrangência, intensidade e a caracterização que atualmente chama atenção.

O outro impacto. e de diferente tipo, diz respeito às sociedades que. quase que repentinamente, são introduzidas num processo intenso sem a condição de entendimento das bruscas transformações: o mais habitual é a concomitância de situações extremas do processo. com decorrências, cuja diversidade é específica de caso para caso, visto que são as condições sociais que explicam os diferentes modos de ação. numa conjugação de esforços que têm a motivação econômica associada a complicados níveis de conquistas tecnológicas.

É a rapidez e intensidade de eventos simultâneas no tempo e no espaço que leva à necessidade urgente e criteriosa de tomada de consciência pela sociedade. Essa sucessão de eventos se explica pela capacidade que a sociedade humana adquiriu em produzir mudanças amplas, extensas e qualitativas.

As mudanças introduzidas levam a reações dos ecossistemas: simplificação do sistema, diminuição de funções. papéis (nichos), redução de cadeias alimentares e outros.

Os ecossistemas alterados fazem funcionar os mecanismos que os regulam. Porém, ao se exceder as possibilidades (limites) dos mecanismos sucede a "ruptura do equilíbrio ecológico"

O aparecimento de novos estados de equilibrio ou de mudanças profundas e irreversíveis (mais comumente após muita acumulaçāo de pequenas e freqüentes mudanças quantitativas) depende do ecossistema em questão. bem como da intensidade, qualidade e duração das modificações introduzidas. 
A ecologia pode orientar nos vários aspectos de:

- determinação da aptidão dos ecossistemas para sua utilização:

- orientação para seleção de tecnologias adequadas para exploração racional:

- enfoque integral do manejo dos ecossistemas a fim de compatibilizar interesses de exploração econômica com oportunidades e limitações dos ecossistemas.

A ecologia, como se observa, auxilia, subsidia, se faz indispensável em uma série de questões fundamentais e urgentes da sociedade. Porém. ecologia e meio ambiente humano não se confundem, não são sinônimos, não são o mesmo. já que o homem não é simplesmente mais um animal do ecossistema. A mediação entre um subsistema e o sistema global (o todo e a parte) não se pode explicar somente com os conceitos, métodos e instrumentos da biologia. Essa mediação é social. Compreender os mecanismos ecológicos que levam à degradação dos ecossistemas é urgente. indispensável, necessário: porém. insuficiente se não se analisam as razões sociais que fazem com que os homens adotem comportamentos que conduzam à deterioração.

O estudo da ecologia isolada da sociedade humana. levando facilmente a uma identificação, colagem de meio ambiente humano com ecologia, levou a uma série de posições de preservação (não é sinônimo do conceito atual de conservação). dos ecossistemas por si. Essa atitude. aparentemente tão bem intencionada e simpática. é quase tão regressiva como a destruição irresponsável dos ecossistemas. A exclusão do homem não se faz de forma indiscriminada e global: é seletiva.

Esse tipo de preservacionismo, adotado de forma ampla, antes de mais nada congela a brecha entre desenvolvimento e subdesenvolvimento.

Abordar os ecossistemas, enquanto propiciadores de recursos (atuais ou potenciais) para uso humano, é uma ótica que desloca as proposições de simplesmente não alterar os ecossistemas para proposições em que se programam as alterações para usos humanos mais eficientes (em alguns casos os programas poderão também não se alterar. conforme as situações específicas).

$\mathrm{O}$ conhecimento do meio ambiente exige a análise das vinculações entre as estruturas do suporte ecológico e as estruturas sociais. É decorrência de entendimento de meio ambiente humano como o resultado de interações entre sistemas ecológicos e sistemas sociais. 
Nas interações são fatores predominantes:

a qualidade (estabilidade e renovação e a quantidade atual e potencial) dos recursos:

a estrutura de relações estabelecidas entre os homens em face dos produtos dos recursos (nos níveis internacional, nacional e local):

o grau de desenvolvimento e a modalidade das tecnologias utilizadas.

As combinações desses fatores determinam:

um certo modelo de utilização de recursos, o que implica um certo tipo de racionalidade política e econômica na utilização dos mesmos:

um certo modelo de utilização do espaço nacional ou regional, rural ou urbano, como expressão física das relações de produção.

Os dois modelos são imbricados e isso se reflete, em cada particular tempo e espaço, na geração de determinadas paisagens que contribuem para definir as condições de qualidade de vida das populações que se vinculam direta e indiretamente a esses modelos.

Poder-se-ia dizer, por alguns dos aspectos sintetizados, que é antropológica a capacidade de conceber transformações. A ótica dos ecossistemas como propiciadores de recursos nos leva à programação da utilização dos espaços como modelos imbricados e tendo como objetivo precípuo o bem-estar social. E a capacidade de projetar as transformações para a qualidade de vida que fica embutida na qualidade ambiental. As transformações se dão por FORMAS no espaço. criando paisagens que assumem consistência. significado, quando compreendidas as inter-relações mais abrangentes. Estas conduzem a implicações de desenho (desígnio, projeto), sem o que os tratamentos paisagísticos não passarão de irônicos cosméticos. São as paisagens o cotidiano de vida do cidadão. São esses os lugares que ele se apercebe, em que ele se identifica, em que ele exerce sua socialização. E, é também nelas e por intermédio delas que se poderá facilitar o avanço da autonomia dos grupos sociais na decisão e controle dos processos de desenvolvimento. Aos outros atores sociais, quais o Estado e os profissionais (dentro e fora do Estado), não são vedadas as iniciativas de proposições para atuações definidas pela sociedade. Problemas a resolver surgirão em todas as dimensões espaciais (escalas) e em todos os campos. Em cada um, os efeitos diretos, indiretos e secundários sobre os demais deverão ser analisados para as proposições dos problemas específicos a resolver.

Texto originalmente publicado no Paisagem e Ambiente - Ensaios II.

(*) Arquiteta paisagista. professora titular e doutora pela FAUUSP. pesquisadora e orientadora do Grupo de Disciplinas Paisagem e Ambiente do Departamento de Projeto FAUUSP. 